http://dx.doi.org/10.21707/gs.v11.n04a02

\title{
ESCARIFICAÇÃo QUÍMICA COMO MÉTODO EFICIENTE PARA SUPERAÇÃO DA dormência de Sementes de Lonchocarpus sericeus (Poir.) Kunth EX DC. (FABACEAE)
}

\author{
Ayslan Trindade Lima ${ }^{1 *}$, Marcos Vinicius Meiado ${ }^{1}$
}

${ }^{1}$ Laboratório de Fisiologia de Sementes, Departamento de Biociências, Universidade Federal de Sergipe. Av. Vereador Olimpio Grande, s/n, Bloco D, Campus Professor Alberto Carvalho, Bairro Porto, Itabaiana, Sergipe, Brasil. CEP: 49510-200.

*Autor para correspondência: tl.ayslan@gmail.com

Recebido em 11 de novembro de 2016. Aceito em 7 de junho de 2017. Publicado em 30 de dezembro de 2017.

REsumo - A dormência é uma característica adaptativa que proporciona a permanência das sementes e a sobrevivência de espécies nos diferentes ecossistemas, mesmo em períodos desfavoráveis para a germinação e o estabelecimento de novos indivíduos. Este estudo teve como objetivo avaliar a eficiência da escarificação de sementes de Lonchocarpus sericeus (Poir.) Kunth ex DC. (Fabaceae) com ácido sulfúrico, a fim de aumentar e sincronizar a germinação das sementes. Para avaliar a eficiência da escarificação das sementes foram estabelecidos seis tratamentos: 0 (controle), 5, 15, 30, 60 e 120 minutos de imersão em ácido sulfúrico concentrado. Após o tratamento com ácido, as sementes foram colocadas para germinar em placas de Petri mantidas em câmaras de germinação sob fotoperíodo de 12 horas e temperatura de $25{ }^{\circ} \mathrm{C}$, sendo avaliadas diariamente, durante um período de 15 dias. Após os 15 dias de avaliação, a germinabilidade das sementes que não passaram pelo tratamento de escarificação química (sementes controle) foi inferior a 5\%, indicando que as sementes da espécie estudada apresentam dormência física, a qual precisa ser superada para que ocorra a germinação. O melhor tratamento para a superação da dormência foi a imersão em ácido sulfúrico concentrado por 15 minutos, devido ao fato desse tratamento ter proporcionado uma maior germinabilidade ( $\geq 95 \%$ ), bem como uma germinação mais rápida e sincronizada, sendo este o método indicado para a superação da dormência das sementes que poderão ser utilizadas para a produção de mudas dessa espécie.

Palavras-chave: CaAtinga; Dormêncla; EscarificaçAo; FabaCeae; Germinaç̃o de Sementes.

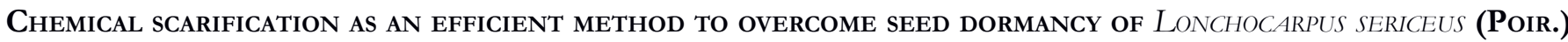
Kunth ex DC. (FABACEAE)

Abstract - The dormancy is an adaptive feature that provides the permanence of the seeds and the survival of species in different ecosystems, even in unfavorable periods for germination and establishment of new individuals. This study aimed to evaluate the efficiency of the scarification of seeds of Lonchocarpus sericeus (Poir.) Kunth ex DC. (Fabaceae) with sulfuric acid in order to increase and synchronize the seed germination. To evaluate the efficiency of seed scarification, six treatments were established: 0 (control), 5, 15, 30, 60 and 120 minutes of immersion in concentrated sulfuric acid. After the acid treatment, the seeds were germinated in Petri dishes maintained in germination chambers under photoperiod of 12 hours and a temperature of $25^{\circ} \mathrm{C}$ and evaluated daily for a period of 15 days. After 15 days of evaluation, the germinability of the seeds that were not underwent the treatment of chemical scarification (control seeds) was less than $5 \%$, indicating that the seeds of the studied species have physical dormancy, which must be overcome to occur germination. The best treatment to overcome dormancy was immersion in concentrated sulfuric acid for 15 minutes due to the fact that this treatment provided greater germination $(\geq 95 \%)$, as well as a faster and synchronized germination. 
Therefore, this is the indicated method to overcome dormancy of seeds that can be used for the production of seedlings of this species.

Keywords: CaATinga; Dormancy; S CARification; FabaCEAE; SEED Germination.

ESCARIFICACIÓN QUIMIICA COMO UN MÉTODO EFICIENTE PARA SUPERAR LA DORMICIÓN DE LAS SEMILLAS DE LONCHOCARPUS sericeus (Poir.) Kunth ex DC. (Fabaceae)

RESUMEN - La dormición es una característica adaptativa que proporciona la permanencia de las semillas y la supervivencia de las especies en diferentes ecosistemas, incluso en los periodos desfavorables para la germinación y el establecimiento de nuevos individuos. Se objetivó en este estudio evaluar la eficiencia de la escarificación de las semillas de Lonchocarpus sericeus (Poir.) Kunth ex DC. (Fabaceae) con ácido sulfúrico para aumentar y sincronizar la germinación. Para evaluar la eficiencia de la escarificación de las semillas se establecieron seis tratamientos: 0 (testigo), 5, 15, 30, 60 y 120 minutos de inmersión en ácido sulfúrico concentrado. Se colocaron las semillas para germinar en cajas Petri introducidas en cámaras de germinación a $25^{\circ} \mathrm{C}$ e iluminación de 12 horas. Después de 15 días de evaluación, se observó que la germinación de las semillas que no han sido sometidas a la escarificación química (semillas del tratamiento testigo) fue inferior al 5\%, lo que indica que las semillas de la especie estudiada tienen dormición física que debe ser eliminada para la germinación. Se observó que la inmersión de las semillas en ácido sulfúrico por 15 minutos fue el mejor tratamiento para la superación de la dormición de las semillas porque proporcionó una germinabilidad superior al 95\%, además de una germinación más rápida y sincronizada. Así, este es el método más indicado para la superación de la dormición de las semillas y debe ser utilizado para la producción de plántulas de esta especie.

Palabras-clave: CaAtinga; Dormición; Escarificación; Fabaceae; Germinación de las Semillas.

\section{INTRODUÇÃo}

Sementes viáveis podem não germinar mesmo em condições ambientais favoráveis ao processo de germinação como disponibilidade hídrica, temperatura, luz e gases (Bewley, 1997). Essas sementes, denominadas sementes dormentes, apresentam restrição à germinação e a superação dessa dormência é necessária para que o processo germinativo se inicie (Cardoso, 2008; Baskin e Baskin, 2014). A presença de dormência nas sementes é uma importante característica adaptativa nas plantas, permitindo o controle de onde e quando a semente poderá germinar e a plântula se estabelecer (Penfield e King, 2009). Evolutivamente, a dormência é uma característica adaptativa que proporciona a permanência das sementes e a sobrevivência de espécies nos diferentes ecossistemas, mesmo em períodos desfavoráveis para a germinação e estabelecimento de novos indivíduos (Vivian et al., 2008; Baskin e Baskin, 2014).

Existem diferentes mecanismos de dormência nas sementes (Zaidan e Barbedo, 2004; Baskin e Baskin, 2014). Entre esses mecanismos, têm-se a dormência física ou tegumentar que é causada pela impermeabilidade dos tecidos da semente, restringindo, assim, a absorção de água e a reativação do metabolismo proporcionada pela embebição (Perez, 2004; Baskin e Baskin, 2014). Entre os métodos de superação de dormência tegumentar, o mais comumente utilizado para escarificação é a imersão da semente em ácido sulfúrico concentrado $\left(\mathrm{H}_{2} \mathrm{SO}_{4}\right)$, onde a eficiência do método está relacionada à quantidade de sementes escarificadas e ao reduzido tempo de imersão no reagente químico (Zaidan e Barbedo, 2004; Albuquerque et al., 2007).

Diversas famílias botânicas apresentam tegumento impermeável em suas sementes. Nas espécies da família Fabaceae, essa é uma característica frequente, principalmente nos representantes dessa família que ocorrem 
na Caatinga, onde a dormência tegumentar representa o tipo de dormência mais observada das sementes que são produzidas nesse ecossistema semiárido (Meiado et al., 2012). Lonchocarpus sericeus (Poir.) Kunth ex DC. é uma dessas espécies da família Fabaceae que ocorre com frequência nas matas ciliares da Caatinga. As matas ciliares são formações florestais que estão em associação com as margens de cursos de água (Bergamin, 2012). Conforme Castro et al. (2012), as matas ciliares são reguladoras do fluxo de água, protegem as margens dos rios contra erosão e mantêm a qualidade da água, uma vez que reduzem os processos erosivos a partir do momento que diminuem o impacto direto da chuva no solo, agindo como filtros que reduzem o escoamento de partículas e sedimentos superficiais. Tais formações vegetais representam grande parte das Áreas de Preservação Permanente (APPs), definida pela Lei de Proteção da Vegetação Nativa, Lei no 12.651, de 25 de maio de 2012, como "área protegida, coberta ou não por vegetação nativa, com a função ambiental de preservar os recursos hídricos, a paisagem, a estabilidade geológica e a biodiversidade, facilitar o fluxo gênico de fauna e flora, proteger o solo e assegurar o bem-estar das populações humanas" (Brasil, 2012).

Os locais de matas ciliares degradados são áreas que requerem prioridade em ações de recuperação, uma vez que margeiam cursos d'água e têm um papel importante na conservação da biodiversidade, na preservação da qualidade dos recursos hídricos e na formação de corredores ecológicos (Macedo, 1993). Diante do exposto e sabendo da importância do cultivo de espécies constituintes das matas ciliares para recuperação de áreas degradas, este estudo teve como objetivo avaliar a eficiência da escarificação de sementes de L. sericeus com ácido sulfúrico, a fim de aumentar e sincronizar a germinação das sementes, otimizando a produção de mudas dessa espécie.

\section{Material e Métodos}

\section{Espécie estudada e local de coleta das sementes}

Lonchocarpus sericeus é uma árvore popularmente conhecida como falso-ingá que pode atingir de 4-20 m de altura. É uma planta perenifólia, heliófita, seletiva higrófita, pioneira ou secundária, típica de matas ciliares em formações classificadas como primárias ou secundárias, ocorrendo, preferencialmente, ao longo de cursos d'água (Lorenzi, 2009). A espécie não é endêmica do Brasil e pode ser encontrada em matas ciliares de diversos domínios fitogeográficos brasileiros como, por exemplo, a Amazônia, a Caatinga, o Cerrado e a Mata Atlântica (Silva e Tozzi, 2016).

Para a coleta dos frutos foram selecionadas 15 matrizes da espécie estudada, as quais estavam às margens do Rio Vaza Barris, no município de Pedra Mole, no Estado de Sergipe. Os frutos foram coletados das matrizes selecionadas e levados para o beneficiamento das sementes no Laboratório de Fisiologia de Sementes (LAFISE) da Universidade Federal de Sergipe, em Itabaiana (SE), onde também foram realizados os experimentos. Os frutos foram abertos manualmente e as sementes foram desinfestadas com solução de hipoclorito de sódio a $10 \%$, durante 5 minutos.

\section{Tratamentos de escarificação quimica}

Para avaliar a eficiência da escarificação das sementes de L. sericeus em ácido sulfúrico foram estabelecidos 
seis tratamentos: 0 (controle), 5, 15, 30, 60 e 120 minutos de imersão em ácido sulfúrico concentrado. As sementes passaram pelos respectivos tempos de imersão no ácido em béqueres de vidro e, em seguida, foram lavadas em água corrente por cinco minutos. Após passarem pelos tratamentos, as sementes foram submetidas ao teste de germinação, utilizando-se quatro repetições de 25 sementes colocadas para germinar em placas de Petri de $9 \mathrm{~cm}$ de diâmetro, contendo duas camadas de papel filtro umedecidas com $15 \mathrm{~mL}$ de água destilada.

O critério utilizado para considerar as sementes germinadas foi a protrusão radicular. As placas de Petri foram mantidas em câmaras de germinação sob fotoperíodo de 12 horas e temperatura de $25^{\circ} \mathrm{C}$, sendo avaliadas diariamente, durante um período de 15 dias.

\section{Parâmetros de germinação e análise estatística}

Após as avaliações, foram calculados, no software GerminaQuant 1.0 (Marques etal., 2015), a germinabilidade $(\mathrm{G}=\%)$, o tempo médio de germinação [TMG $=\sum n_{i} t_{i} / \sum n_{i}$ onde $t_{i}$ é o período desde o início do experimento até a enésima observação (dias) e $n_{i}$ é o número de sementes germinadas no tempo $i$ e o índice de sincronização da germinação $\left[\mathrm{Z}=\sum \mathrm{C}_{i}, 2 / \mathrm{C}_{\sum n i, 2}\right.$, onde $\left.\mathrm{C}_{i}, 2=n_{i}\left(n_{i}-1\right) / 2\right]$. Além disso, foi calculado também o índice de velocidade de germinação $\left[\mathrm{IVG}=\left(\mathrm{G}_{1} / \mathrm{N}_{1}\right)+\left(\mathrm{G}_{2} / \mathrm{N}_{2}\right)+\left(\mathrm{G}_{3} / \mathrm{N}_{3}\right)+\ldots+\left(\mathrm{G}_{\mathrm{n}} / \mathrm{N}_{\mathrm{n}}\right)\right.$, onde $\mathrm{G}_{1}, \mathrm{G}_{2}, \mathrm{G}_{3}, \ldots, \mathrm{G}_{\mathrm{n}}$ corresponde ao número de sementes germinadas na primeira, segunda, terceira e última contagem e $\mathrm{N}_{1}, \mathrm{~N}_{2}, \mathrm{~N}_{3}$, ..., $\mathrm{N}_{\mathrm{n}}$ corresponde ao número de dias da semeadura à primeira, segunda, terceira e última contagem (Maguire, 1962)], a frequência relativa de germinação $\left[f_{i}=n_{i} / \sum n_{i}\right]$ e a mortalidade $(\mathrm{M}=\%)$ das sementes após a protrusão da radícula.

Os resultados de todos esses parâmetros foram analisados pela ANOVA, com teste de Tukey a posteriori. A germinabilidade foi transformada em arcoseno $\sqrt{ } \%$ antes das análises e a normalidade dos dados e a homogeneidade das variâncias foram verificadas através dos testes Levene e Shapiro-Wilk, respectivamente. Os tratamentos que proporcionaram uma germinabilidade inferior a 5\% foram retirados das análises dos demais parâmetros de germinação. Todas as análises estatísticas foram realizadas no programa BioEstat 5.3 com índice de significância de 0,05 (Ayres et al., 2007).

\section{RESUltados}

As sementes de L. sericeus começaram a germinar no segundo dia após o início do experimento, quando estas foram submetidas aos tratamentos de imersão em ácido sulfúrico (Figura 1). Após os 15 dias de avaliação, a germinabilidade das sementes que não passaram pelo tratamento de escarificação química (sementes controle) foi inferior a 5\% (Tabela 1), indicando que as sementes da espécie estudada apresentam dormência física ou tegumentar, a qual precisa ser superada para que ocorra a germinação.

Analisando-se todos os parâmetros de germinação calculados no presente estudo, foi possível determinar o melhor tratamento para a superação da dormência tegumentar das sementes da espécie estudada, o qual correspondeu ao tratamento de imersão em ácido sulfúrico concentrado por 15 minutos, devido ao fato desse tratamento ter proporcionado uma maior germinabilidade $(\geq 95 \%)$, bem como uma germinação mais rápida e sincronizada (Tabela 1). Além disso, não foi observada a mortalidade de nenhuma semente germinada após a passagem pelo ácido sulfúrico por 15 minutos e todas as sementes formaram plântulas normais, indicando 
que esse tratamento é o mais favorável para a superação da dormência tegumentar de sementes de L. sericeus, podendo ser indicado para a produção de mudas dessa espécie.

Tabela 1 - Germinabilidade (G = \%), tempo médio de germinação (TMG = dias), índice de sincronização da germinação $(Z)$, índice de velocidade de germinação (IVG) e mortalidade (M = \%) de sementes de Lonchocarpus sericeus (Poir.) Kunth ex DC. (Fabaceae) após diferentes tempos de imersão em ácido sulfúrico $\left(\mathrm{H}_{2} \mathrm{SO}_{4}\right)$ para superação de dormência tegumentar. Dados expressos em média \pm desvio padrão.

\begin{tabular}{cccccc}
\hline Tratamento & $\mathbf{G ~ ( \% )}$ & TMG (dias) & $\mathbf{Z}$ & IVG & M (\%) \\
\hline Controle & $3,0 \pm 3,8 \mathrm{c}$ & - & - & - & $0 \mathrm{~b}$ \\
$\mathbf{5}$ minutos & $98,0 \pm 2,3 \mathrm{a}$ & $3,0 \pm 0,1 \mathrm{a}$ & $0,35 \pm 0,05 \mathrm{~b}$ & $8,45 \pm 0,55 \mathrm{~b}$ & $0 \mathrm{~b}$ \\
$\mathbf{1 5}$ minutos & $95,0 \pm 5,0 \mathrm{a}$ & $2,3 \pm 0,2 \mathrm{ab}$ & $0,54 \pm 0,12 \mathrm{a}$ & $10,42 \pm 0,75 \mathrm{a}$ & $0 \mathrm{~b}$ \\
$\mathbf{3 0}$ minutos & $28,0 \pm 8,9 \mathrm{~b}$ & $3,4 \pm 0,6 \mathrm{a}$ & $0,33 \pm 0,09 \mathrm{~b}$ & $2,29 \pm 0,93 \mathrm{c}$ & $0 \mathrm{~b}$ \\
$\mathbf{6 0}$ minutos & $25,0 \pm 5,0 \mathrm{~b}$ & $2,1 \pm 0,2 \mathrm{~b}$ & $0,71 \pm 0,32 \mathrm{a}$ & $2,95 \pm 0,77 \mathrm{c}$ & $100 \mathrm{a}$ \\
$\mathbf{1 2 0}$ minutos & $1,0 \pm 2,0 \mathrm{c}$ & - & - & - & $100 \mathrm{a}$ \\
\hline $\mathbf{F}$ & 114,5450 & 11,0286 & 3,8901 & 109,3121 & 1,0000 \\
$\mathbf{g} \mathbf{l}$ & 5 & 3 & 3 & 3 & 5 \\
$\mathbf{p}$ & $<0,0001$ & 0,0012 & 0,0370 & $<0,0001$ & $<0,0001$ \\
\hline
\end{tabular}

O tempo de imersão em ácido sulfúrico afetou significativamente todos os parâmetros de germinação avaliados no presente estudo. Os tratamentos de menor tempo de exposição ao ácido (5 e 15 minutos) foram suficientes para superar a dormência tegumentar das sementes e proporcionar as maiores germinabilidades observadas, atingindo valores superiores a 95\% (Tabela 1). Por outro lado, quando as sementes foram submetidas a mais de 30 minutos de ácido sulfúrico concentrado, foi observada uma drástica redução da germinabilidade, a qual atingiu valores inferiores a 5\% quando as sementes da espécie estudada permaneceram 120 minutos em contato com o ácido que proporcionou a sua escarficação (Figura 1).

A frequência relativa da germinação das sementes de L. sericeus também indicou que o tratamento de imersão em ácido sulfúrico por 15 minutos foi o melhor para a superação da dormência tegumentar dessa espécie (Figura 1). Dentre as curvas de germinação da figura 1, a melhor distribuição da frequência relativa de germinação foi a do tratamento 15 minutos, onde se observou um comportamento mais leptocúrtico da curva, com distribuição unimodal e maior porcentagem da frequência relativa de germinação em um menor espaço de tempo. Esse comportamento germinativo descrito acima também sugere uma germinação mais sincronizada nesse tratamento. De fato, o índice de sincronização da germinação das sementes de L. sericeus foi influenciado pelo tempo que as sementes passaram em contato com o ácido sulfúrico, sendo possível observar uma germinação mais sincronizada no tratamento de imersão em ácido por 15 minutos, corroborando, mais uma vez, a eficiência desse tratamento na superação da dormência das sementes da espécie avaliada no presente estudo.

Diferenças significativas no TMG e no IVG também foram observadas quando as sementes de L. sericeus foram submetidas aos diferentes tempos de imersão em ácido sulfúrico concentrado. O menor TMG foi observado quando as sementes foram imersas em ácido por 60 minutos, mas esse tratamento proporcionou um TMG estatisticamente igual ao tratamento de 15 minutos, o qual apresentou uma das maiores germinabilidade observadas no presente estudo (Tabela 1). Além disso, o maior IVG também foi observado no tratamento de 15 minutos de imersão em ácido sulfúrico concentrado, indicando, novamente, que este representou a melhor forma de superar a dormência tegumentar da espécie estudada (Tabela 1). 
Figura 1 - Frequência relativa da germinação (\%) de sementes de Lonchocarpus sericeus (Poir.) Kunth ex DC. (Fabaceae) após diferentes tempos de imersão em ácido sulfúrico $\left(\mathrm{H}_{2} \mathrm{SO}_{4}\right)$ para superação de dormência tegumentar.

Controle

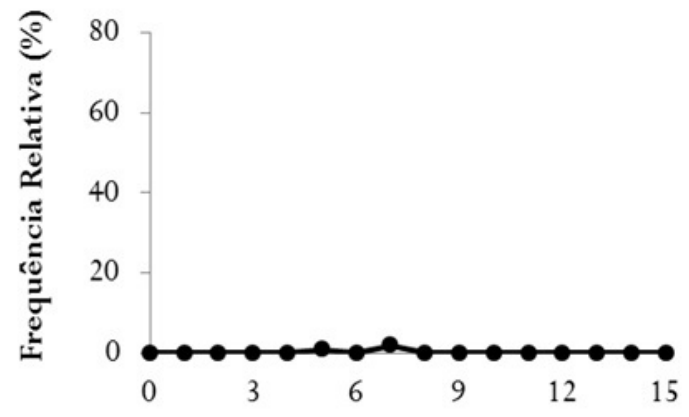

15 minutos

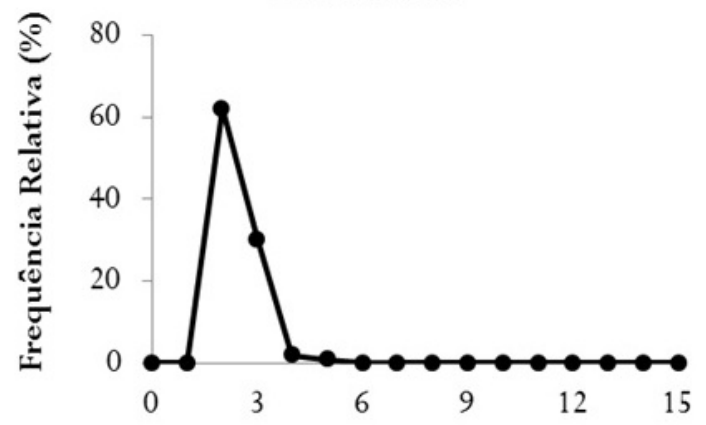

60 minutos

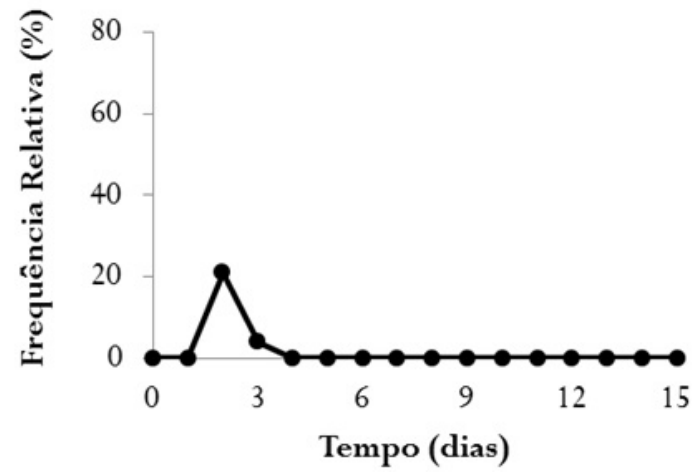

5 minutos

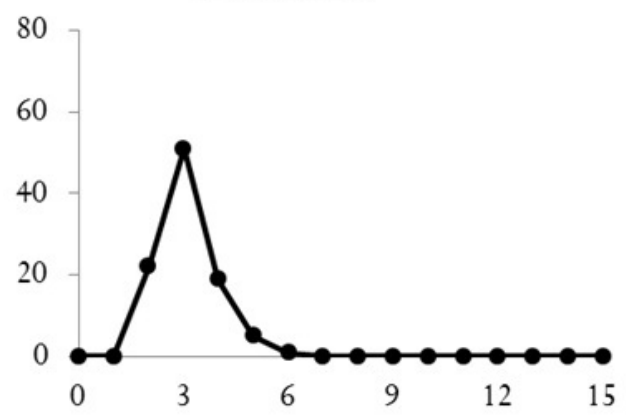

30 minutos

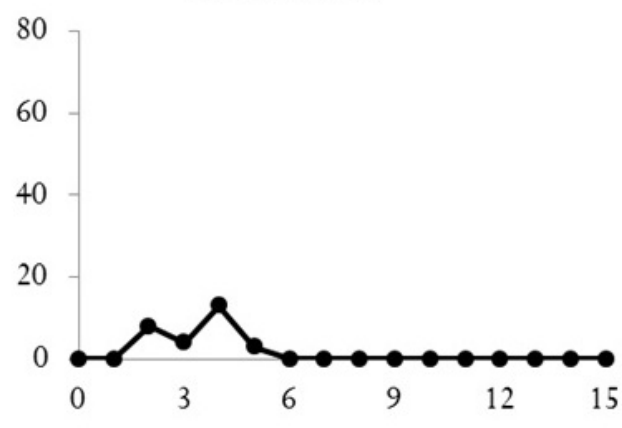

120 minutos

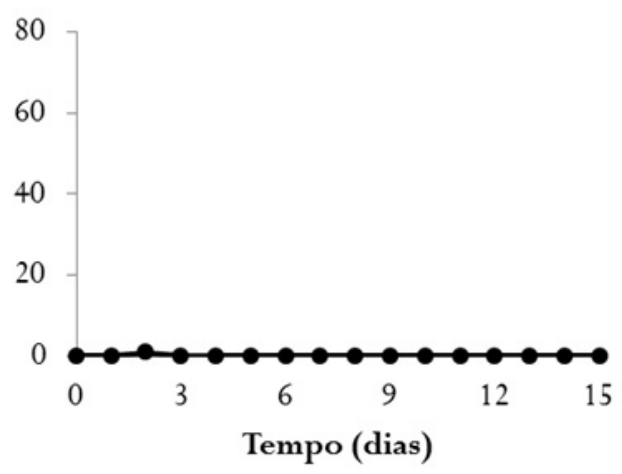

Embora tenha sido observada uma germinabilidade superior a 25\% nos tratamentos de imersão em ácido sulfúrico por um período de 60 e 120 minutos, todas as sementes germinadas da espécie estudada morreram após a protrusão radicular. Por outro lado, não foi observada a mortalidade de nenhuma semente de L. sericeus submetida a um tempo de imersão em ácido sulfúrico $\leq 30$ minutos (Tabela 1).

\section{Discussão}

Plantas que produzem sementes com dormência física ou tegumentar, como a espécie avaliada no presente estudo, apresentam algumas vantagens que podem favorecer o sucesso reprodutivo dessas espécies e facilitar a sua ocorrência em ecossistemas com fatores ambientais limitantes e estressantes como, por exemplo, temperaturas elevadas, alta exposição solar e baixa disponibilidade hídrica no solo. Esses benefícios estão relacionados, principalmente, à proteção que esses tegumentos rígidos e impermeáveis proporcionam às sementes, permitindo que o embrião esteja protegido desses fatores ambientais extremos e possa se desenvolver quando encontrar as 
condições favoráveis para a germinação (Meiado et al., 2012; Baskin e Baskin, 2014). Além disso, a presença de tegumentos rígidos e impermeáveis reduz o ataque de predadores de sementes no período de pós-dispersão e permite que esses diásporos sejam manipulados e/ou consumidos por diferentes animais, sem que haja um dano significativo ao embrião, proporcionando uma maior distribuição das sementes de espécies que apresentam esse tipo de dormência (Fenner e Thompson, 2005).

Por outro lado, a dormência física ou tegumentar representa uma barreira ao processo de embebição que é crucial para a reidratação dos tecidos das sementes e para a reativação do metabolismo celular que ocasionarão a germinação (Baskin e Baskin, 2014). Como visto nos resultados deste estudo, quando a dormência das sementes não é superada, a germinação não ocorre e, nesse caso, a produção de mudas ficará comprometida. Existem diversas técnicas de laboratórios desenvolvidas para a superação da dormência física ou tegumentar (Zaidan e Barbedo, 2004). As mais usuais se referem à utilização de lixas ou substratos abrasivos que tem por objetivo remover parte do tegumento impermeável e proporcionar a entrada de água na semente (escarificação física), bem como a utilização de reagentes químicos como, por exemplo, ácidos clorídrico ou sulfúrico, com a mesma finalidade de remover parte do tegumento impermeável e proporcionar a germinação das sementes (escarificação química). Ainda há espécies onde a dormência física ou tegumentar pode ser superada submetendo-se as sementes a uma rápida variação de temperatura que proporciona a rachadura dos tegumentos e, consequentemente, a entrada de água que ocasionará a germinação (escarificação térmica). Nem todas as técnicas funcionam de maneira semelhante em sementes de diversas espécies e a determinação da melhor forma de superação da dormência física ou tegumentar é essencial para garantir a eficiência na produção de mudas de espécies nativas que apresentam esse tipo de dormência (Carvalho e Nakagawa, 2000; Zaidan e Barbedo, 2004; Baskin e Baskin, 2014).

Como visto nos resultados do presente estudo, a utilização de ácido sulfúrico concentrado se mostrou eficaz na superação da dormência de L. sericeus. A dormência física ou tegumentar de outras espécies nativas também foi superada de forma eficaz com a utilização de ácidos sulfúrico, porém, em intervalos de tempo diferenciados. Sementes de Bowdichia virgilioides Kunth (Fabaceae) foram submetidas a tratamentos de imersão em ácido sulfúrico por diferentes intervalos de tempo, sendo constatado que o melhor tratamento para promover a germinação das sementes dessa espécie foi a imersão em ácido sulfúrico por um período de 5 minutos (Albuquerque et al., 2007). Já a dormência das sementes de Tectona grandis L.f. (Lamiaceae) também é superada com a utilização de ácido sulfúrico por 3 minutos (Dias et al., 2009) e as sementes de Caesalpinia leiostachya (Benth.) Ducke (Fabaceae) precisam estar em contato com o ácido sulfúrico por um período de 20 a 30 minutos para que a dormência dessa espécie seja superada (Biruel et al., 2007). Por sua vez, o melhor tratamento para a superação da dormência tegumentar das sementes de Stryphnodendron adstringens (Mart.) Coville (Fabaceae) é a imersão em ácido sulfúrico por um período de 60 minutos, o qual proporciona a abertura no tegumento impermeável para a passagem de água, permitindo a embebição das sementes e sua germinação (Martins e Nakagawa, 2008).

Perez (2004) destaca a importância do tempo de exposição das sementes ao ácido, pois, quando excedido esse tempo ótimo de escarificação, podem ocorrer danos ao eixo embrionário, resultando em perda de vigor e da viabilidade da semente. Isso explica a baixa porcentagem de germinação observada nos tratamentos de 30 , 60 e 120 minutos aplicados nas sementes de L. sericeus no presente estudo, além de justificar a alta mortalidade (100\%) observada nos tratamentos 60 e 120 minutos de exposição ao ácido sulfúrico concentrado.

Assim como foi observado nos resultados deste estudo, sementes de Ormosia nitida Vogel (Fabaceae) 
que foram imersas em ácido sulfúrico concentrado por um período de 15 minutos também apresentaram um comportamento leptocúrtico nas curvas de frequência relativa de germinação, com deslocamento do tempo médio para a esquerda, indicando um aumento na velocidade do processo germinativo e, assim, caracterizando o melhor tratamento para a superação da dormência tegumentar dessa espécie (Lopes et al., 2006). Isso se deve ao fato de que as sementes escarificadas no tempo ideal de imersão no ácido sulfúrico, livres da impermeabilidade do tegumento, absorvem quantidades suficientes de água para reativar seu metabolismo e finalizar o processo de germinação em um espaço de tempo menor, quando comparadas aos outros tratamentos avaliados (Lopes et al., 2006).

A resposta da velocidade de germinação em relação ao tempo de imersão das sementes em ácido sulfúrico pode ser observada comparando-se os dados de IVG obtidos no presente estudo, onde o tratamento 15 minutos apresentou o maior índice e com diferença significativa entre os demais tratamentos avaliados. Cruz et al. (2007), avaliando sementes de Schizolobium parabyba (Vell.) Blake var. amazonicum (Huber ex Ducke) Barneby (Fabaceae) e Malavasi e Malavasi (2004), avaliando sementes de Enterolobium contortisiliquum (Vell.) Morong (Fabaceae), também utilizaram os valores mais altos de IVG para determinar os melhores tempos de imersão em ácido sulfúrico para a superação da dormências dessas duas espécies arbóreas e observaram diferenças significativas no IVG quando as sementes foram submetidas a diferentes tempos de imersão em ácido sulfúrico.

Diante do exposto, conclui-se que as sementes de L. sericeus apresentam dormência física ou tegumentar e que o tratamento mais eficiente para a superação da dormência das sementes dessa espécie é a imersão em ácido sulfúrico concentrado por um período de 15 minutos, sendo este o método indicado para a superação da dormência das sementes que poderão ser utilizadas para a produção de mudas dessa espécie.

\section{REFERÊNCIAS}

Albuquerque KS, Guimarães RM, Almeida IF e Clemente ACS. 2007. Métodos de superação em sementes de sucupira-preta (Bowdichia virgilioides Kunth). Ciência e Agrotecnologia, 31: 1716-1721.

Ayres M, Ayres Jr. M, Ayres DL e Santos AAS. 2007. BioEstat 5.0. Belém: Instituto Mamirauá. 364p.

Baskin CC e Baskin JM. 2014. Seeds: ecology, biogeography, and evolution of dormancy and germination. San Diego: Academic Press. 666p.

Bergamin RS. 2012. Árvores e arbustos adaptados à correnteza ou submersão eventual. Pp. 18-21. In: Castro D, Mello RSP e Poester GC (Orgs.). Práticas para restauração da Mata Ciliar. Porto Alegre: Catarse.

Bewley JD. 1997. Seed Germination and Dormancy. The Plant Cell, 9: 1055-1066.

Biruel RP, Aguiar IB e Paula RC. 2007. Germinação de sementes de pau-ferro submetidas a diferentes condições de armazenamento, escarificação química, temperatura e luz. Revista Brasileira de Sementes, 29: 151-159.

Brasil. 2012. Lei n 12.651, de 25 de maio de 2012. Brasília: Casa Civil, Subchefia para Assuntos Jurídicos.

Carvalho NM e Nakagawa J. 2000. Sementes: ciência, tecnologia e produção. Jaboticabal: Funep. 588p. 
Castro D, Mello RSP e Poester GC. 2012. Práticas para restauração da Mata Ciliar. Porto Alegre: Catarse. $59 \mathrm{p}$.

Cruz ED, Carvalho JEU e Queiroz RJB. 2007. Scarification with Sulphuric Acid of Schizolobium amazonicum Huber ex Ducke Seeds - Fabaceae. Scientia Agricola, 64: 308-313.

Dias JRM, Caproni AL, Wadt PGS, Silva LM, Tavella LB e Oliveira JP. 2009. Quebra de dormência em diásporos de teca (Tectona grandis L.f.). Acta Amazonica, 39: 549-554.

Fenner M e Thompson K. 2005. The ecology of seeds. Cambridge: Cambridge University Press. 250p.

Lopes JC, Dias PC e Macedo CMP. 2006. Tratamentos para acelerar a germinação e reduzir a deterioração das sementes de Ornosia nitida Vog. Revista Árvore, 30: 171-177.

Lorenzi H. 2009. Árvores brasileiras: Manual de identificação e cultivo de plantas arbóreas nativas do Brasil. Nova Odesa: Instituto Plantarum. 384p.

Macedo AC. 1993. Revegetação: Matas ciliares e de proteção ambiental. São Paulo: Fundação Florestal. $24 \mathrm{p}$.

Maguire JD. 1962. Speed of Germination in Selection and Evolution for Seedling Emergence and Vigor. Crop Science, 2: 176-177.

Malavasi UC e Malavasi MM. 2004. Dormancy breaking and germination of Enterolobium contortisiliquum (Vell.) Morong seed. Brazilian Archives of Biology and Technology, 47: 851-854.

Marques FRF, Meiado MV, Castro NMCR, Campos MLO, Mendes KR, Santos OO e Pompelli MF. 2015. GerminaQuant: A New Tool for Germination Measurements. Journal of Seed Science, 37: 248-255.

Martins CC e Nakagawa J. 2008. Germinação de sementes de Stryphnodendron adstringens (Mart.) Coville de diferentes origens submetidas a tratamentos para superação de dormência. Revista Árvore, 32: 1059-1067.

Meiado MV, Silva FFS, Barbosa DCA e Siqueira Filho JA. 2012. Diaspore of the Caatinga: A Review. Pp. 306365. In: Siqueira Filho JA (Org.). Flora of the Caatingas of the São Francisco River: Natural History and Conservation. Rio de Janeiro: Andrea Jakobsson Estúdio Editorial.

Penfield S e King J. 2009. Towards a systems biology approach to understanding seed dormancy and germination. Proceedings of the Royal Society of London B., 276: 3561-3569.

Perez SCJGA. 2004. Envoltórios. Pp. 125-134. In: Ferreira FB e Borguetti F (Orgs.). Germinação: Do Básico ao Aplicado. Porto Alegre: Artmed.

Silva MJ e Tozzi AMGA. 2016. Lonchocarpus. In: Lista de Espécies da Flora do Brasil. Rio de Janeiro: Jardim Botânico do Rio de Janeiro. Disponível em: < http://floradobrasil.jbrj.gov.br/jabot/floradobrasil/FB29737>. Acesso em: 12 Jun. 2016.

Vivian R, Silva AA, Gimenes Jr. M, Fagan EB, Ruiz ST e Labonia V. 2008. Dormência em sementes de plantas 
daninhas como mecanismo de sobrevivência - Breve revisão. Planta Daninha, 26: 695-706.

Zaidan LBP e Barbedo CJ. 2004. Quebra de dormência em sementes. Pp. 135-146. In: Ferreira FB e Borguetti F (Orgs.). Germinação: Do Básico ao Aplicado. Porto Alegre: Artmed. 